\title{
Are the birds dangerous for insect pollinators? The relationship between hymenopterans and the red-backed shrike
}

\author{
Artur Golawski · Sylwia Golawska
}

Received: 9 January 2013/Accepted: 29 August 2013/Published online: 5 September 2013

(C) The Author(s) 2013. This article is published with open access at Springerlink.com

\begin{abstract}
Studies of the relationships between insectivorous birds and insects have focused on woodland habitats, where insects have usually been regarded as tree pests. But some insects are of the utmost importance to the human economy, especially hymenopterans, which pollinate plants such as fruit trees in orchards. Here we report on a 5-year study of the influence of the red-backed shrike Lanius collurio, a territorial insectivorous bird, on the numbers of hymenopterans in the extensively farmed landscape of eastern Poland. The relevant relationships were based on an analysis of the shrike's diet and the numbers of hymenopterans in and beyond nesting locations. There was a weak but statistically significant relationship between the proportion of hymenopterans in the red-backed shrike's diet and the place and time of prey capture, but this was dependent solely on the location of the shrike's territory. No relationship was found between the numbers of hymenopterans and the presence of the red-backed shrike, agricultural site type or season effect. In conclusion, territorial bird species that occur in low densities probably have only a marginal influence on hymenopterans, including pollinators.
\end{abstract}

Keywords Lanius collurio - Insectivorous birds · Diet analysis · Hymenoptera - Extensive farming landscape

\footnotetext{
A. Golawski $(\square)$

Department of Zoology, Siedlce University of Natural Sciences and Humanities, Prusa 12, 08-110 Siedlce, Poland

e-mail: artgo1@uph.edu.pl

S. Golawska

Department of Biochemistry and Molecular Biology, Siedlce University of Natural Sciences and Humanities, Prusa 12, 08-110 Siedlce, Poland
}

\section{Introduction}

The studies of the relationships between insectivorous birds and insects done to date have focused mainly on woodland habitats, where insects have usually been regarded as tree pests (Marquis and Whelan 1994; Murakami and Nakano 2000; Sanz 2001), or coffee plantations (Greenberg et al. 2000) and orchards (Mols and Visser 2002). Such research has also been conducted in non-forest, open habitats (review in Mooney et al. 2010). Those investigations demonstrated how birds indirectly influenced the foliage of plants and the amount of fruit produced through predation on the natural enemies of plants. But some insects are of the utmost importance to the human economy, especially hymenopterans, which pollinate plants such as fruit trees in orchards. The economic value of global insect pollination has been estimated at billions of USD per year (Gallai et al. 2009; Wratten et al. 2012).

Numbers of hymenopterans, in particular the honey bee Apis mellifera, have fallen dramatically in recent years, but the main reason for this has not yet been found (Yang et al. 2008; Potts et al. 2010; Pettis et al. 2012), and that includes Poland (Semkiw and Skubida 2010). This rapid decline in numbers is a real threat to the normal functioning of agriculture and fruit-growing.

Very few studies have been done on the relationship between birds and these "useful" insects (Muñoz and Arroyo 2004; Meehan et al. 2005), and their results are ambivalent, depending as they do on the bird species concerned. Yet a great many bird species are insectivorous. One of them is the red-backed shrike Lanius collurio: this forages to an overwhelming extent on insects, which usually make up more than $90 \%$ of its diet. Hymenopterans are the preferred food of these shrikes (Hernández et al. 1993; Tryjanowski et al. 2003; Golawski 2006), and their 
proportions can make up as much as $50 \%$ of all prey items (Tryjanowski et al. 2003). These data suggest that this species may be playing a part in shaping the numbers of this order of insects, and thus of insect pollinators.

The aim of this study was to examine the influence of an insectivorous bird like the red-backed shrike on the numbers of hymenopterans in the extensively farmed landscape of eastern Poland, a feature of which is its great diversity, including the insects (Golawski and Golawska 2008).

\section{Materials and methods}

\section{Study area}

The survey was carried out on 855 ha of extensively farmed land in eastern Poland near Siedlce $\left(52^{\circ} 12^{\prime} \mathrm{N}\right.$, $22^{\circ} 17^{\prime} \mathrm{E}$ ) in $1999-2003$. A characteristic feature of this region is the division of arable land into small fields by a large number of wide balks and lanes (Golawski and Meissner 2008). The consumption of pesticides and mineral fertilisers, and in consequence the yield, is scarcely half that in western Europe (Donald et al. 2002; Tryjanowski et al. 2011). Arable fields predominated in this area $(53.5 \%)$, meadows and pastures covered $21.1 \%$ and woodlands $12.3 \%$ of the land. Intensively managed orchards were up to 5 ha in area (47 ha in all; $5.5 \%$ of the study area). The orchards consisted to an overwhelming extent of apple trees Malus domestica; only 1 ha was given over to sour cherries Prunus cerasus. The trees had been planted in rows, and the surface vegetation between the trees was mowed a few times during the 3 months each year of our study. The crops of both tree species were very dependent on insect pollination. The orchards were surrounded by farmland, where lane verges and balks supported large numbers of flowering plants. Red-backed shrikes occupied open habitats on the margins of woodlands and orchards.

The red-backed shrike

The red-backed shrike is a small passerine species widely distributed in the Western Palearctic. It is a long distance migrant, which arrives at its breeding grounds from Africa in early May (Harris and Franklin 2000). A red-backed shrike territory is 1.5 ha in area, and pairs defend it from their arrival until 2-3 weeks after the young birds have fledged. Four to seven eggs are laid and are incubated for 14 days. The nestlings remain in the nest for another 14 days. This species is normally single-brooded, but in case of first brood failure, replacement clutches are laid regularly (Cramp and Perrins 1993). An insectivorous species, the red-backed shrike has a varied diet: among the hymenopterans alone there were species from 12 different families (Kuźniak and Tryjanowski 2003). There are 2.2 million breeding pairs of red-backed shrikes in Europe, and the Polish population is one of the biggest in Europe (Harris and Franklin 2000).

Diet of the red-backed shrike

Analysis of the red-backed shrike's dietary composition was based on an examination of insect remains in pellets and butchering sites and also of the insects in its larders. Since in one locality the remains of the same victim could be found both in pellets and at the butchering sites, the total number of prey items was established from the numbers of individual taxa, taking into account the maximum number obtained by one of the three methods of analysing food composition. The number of insects was determined from the remains characteristic of a given taxon, i.e. heads, legs, parts of or whole elytra (Tryjanowski et al. 2003). The proportion of hymenopterans in the diet was calculated as the ratio of the number of hymenopterans to the total number of prey items in a given sample. Samples containing at least 10 prey items per month per sampling site were taken into consideration; a total of 4,699 such items were found in the food of red-backed shrike. From 6 to 20 samples were taken per year from 1999 to 2003. The redbacked shrike's prey items were searched for in its territories under its regular perches 3-5 times per season from May to July; larger numbers of samples from a month were pooled. In view of brood losses at various stages of breeding and nest site abandonment, from 1 to 3 samples were collected at each site. During the 5 years of the study 54 localities of red-backed shrike were monitored; 21 samples of food were collected from pairs inhabiting orchards and 51 samples from pairs nesting in wild shrubs. Because the red-backed shrike's nest-site fidelity in Poland is low, the probability of the same birds being present in the same localities in consecutive years is likewise low (Tryjanowski et al. 2007).

Numbers of hymenopterans

Data on the numbers of hymenopterans (both those on flowers and those flying past) were collected in 1999 and 2001-2003 using a walking transect method (speed ca $10 \mathrm{~m} / \mathrm{min}$ ) along a path $1 \mathrm{~m}$ wide and $50 \mathrm{~m}$ long at each site. The counts were done by the same person between 11:00 and 14:00 hours at a minimum air temperature of $18{ }^{\circ} \mathrm{C}$ and light wind. These conditions are optimal for the flight activity of hymenopterans and offer a good reflection of their numbers with this method of counting (Holzschuh et al. 2012; Sparks et al. 2010). However, this method missed small species, including Formicidae. Numbers were 
assessed at 13 sites inhabited by red-backed shrikes and at another 13 where these birds were absent. 12 of the 26 transects passed through orchards and 14 through areas supporting wild shrubs. Where red-backed shrikes were found, the transects ran at most $20 \mathrm{~m}$ from the birds' regular perches, which were usually on fences in orchards or pastures, or on single trees or bushes. The birds regularly used these look-out posts for hunting; this was where pellets and food remains were left, or where prey items were impaled on barbed wire or protruding ends of wire netting. The lines of the transects where shrikes had not been found were over $200 \mathrm{~m}$ distant from their localities, but ran through habitats similar to those where the shrikes held territories. Knowledge of the distribution of redbacked shrike territories gathered during the authors' field studies in 1995-1996 and 1998 was helpful in the selection of the transects. Since these shrikes prefer particular habitats (orchards, clumps of trees), the same patches of habitat were occupied in successive years. At least 30 pairs of this species nested in the study area. The 13 transects covering the shrike territories were chosen at random from these 30 possible areas. The transect layout was different each year. Four transects ( 2 each in a shrike territory and beyond it) were monitored in 1999, six (3 each in a shrike territory and beyond it) in 2001 and 2002, and 10 (5 each) in 2003. Each transect was walked 2-4 times from May to July, giving a total of 88 walks.

\section{Statistical analysis}

The effects of agricultural site type (orchard vs. wild shrubs) and season (three months: May, June, July) on the proportion of hymenopterans in the red-backed shrike's diet were assessed using generalized linear mixed models GLMM with normal error distribution and an identity link function. Proportion of hymenopterans in shrike's diet was normalised by its square-root transformation. We also included a year effect into the model. GLMM was used because some of the data on the shrikes' diet came from the same territories which were searched several times a season, and so were not completely independent. "Season effects" and "Year" were treated as a random variable.

GLMM with normal error distribution and an identity link function was also employed for establishing the factors affecting the numbers of hymenopterans, which were made dependent on the presence of red-backed shrike territories, the phenological period (three months-May, June, Julytreated as a random variable), and the habitat type (orchard vs. wild shrubs). We also included a year effect into the model (random variable). The calculations were performed using Statistica 8.0 (StatSoft 2007). Mean values and standard errors are given. Results with $p<0.05$ were assumed to be statistically significant.

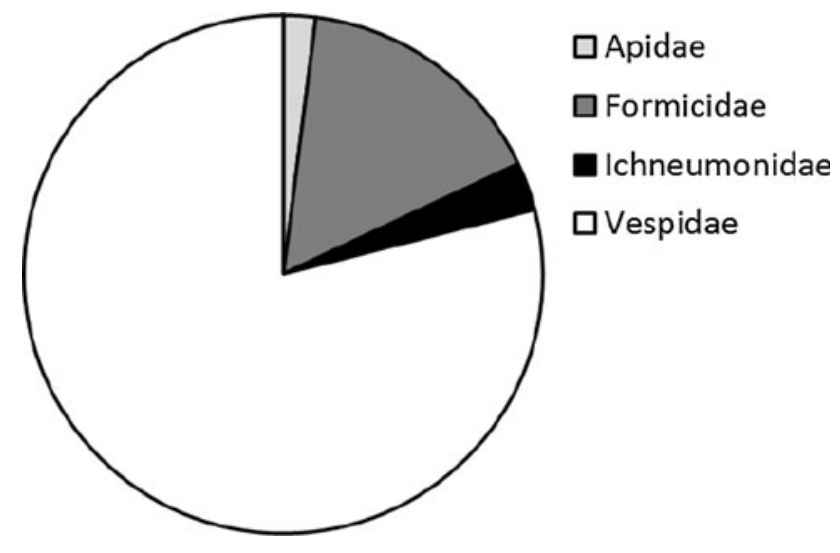

Fig. 1 Proportion of hymenopteran families in the diet of the redbacked shrike in the extensively farmed landscape of eastern Poland

Table 1 Results of the GLMM analysis assessing effect of agricultural site type (orchard vs. wild shrubs), season (May-July) and years on the percentage of hymenopterans in red-backed shrike's diet in the extensively farmed landscape of eastern Poland

\begin{tabular}{lclll}
\hline Variable & Estimate & SE & $F$ & $p$ \\
\hline Agricultural site type & 17.836 & 1.872 & 9.53 & 0.003 \\
Season & 0.632 & 2.197 & 0.29 & 0.751 \\
Year & 0.509 & 2.106 & 0.24 & 0.913 \\
\hline
\end{tabular}

\section{Results}

Four hundred and forty hymenopterans were found in the food of the red-backed shrikes, i.e. $9.4 \%$ of the total of 4,699 prey items. The vast majority were from the family Vespidae (79 \%), followed by Formicidae, Ichneumonidae and Apidae, the last-mentioned making up barely $2 \%$ (Fig. 1). There was a statistically significant relationship between the proportion of hymenopterans in the red-backed shrike diet and the location of shrike territories (Table 1). Hymenopteran prey items were proportionally more frequent in wild shrubs than in orchards (Fig. 2). The proportion of hymenopterans in the diet was very similar in particular months: May-11.3 $\pm 4.73 \% \quad(n=7), \quad$ June-9.5 $\pm 1.36 \%$ $(n=33)$ and July-10.6 $\pm 1.41 \%(n=32)$ and didn't change with season and years (Table 1).

One hundred and sixty-one hymenopterans were found during the transect counts, an average of 1.8 ( $\mathrm{SE}=0.21$, $n=88$ ) per walk (Table 2). Even though the abundance of these insects increased in consecutive months, their overall numbers remained low and the increase was marginally significant (Table 3; Fig. 3). No relationship was found between the numbers of hymenopterans and the presence of the red-backed shrike, years or agricultural site type (Table 2). 


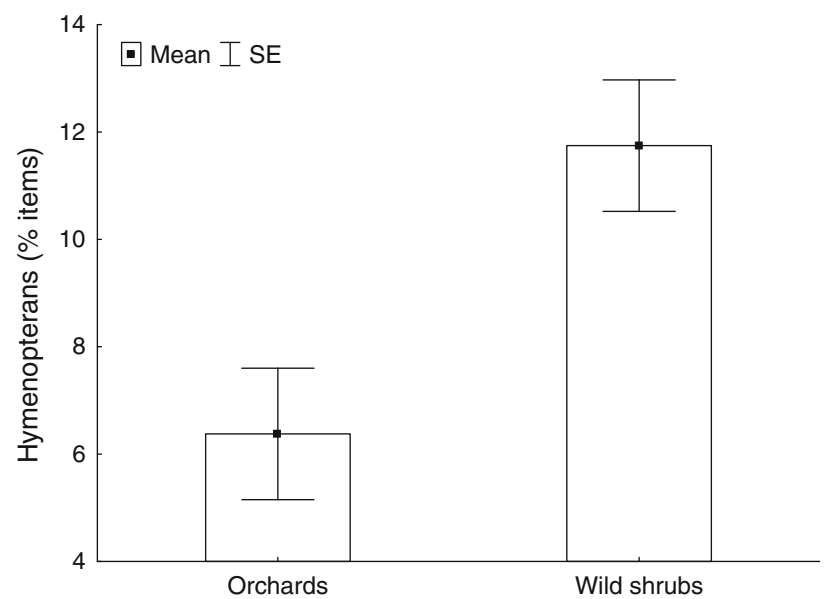

Fig. 2 Mean proportion of hymenopterans (\%) in the diet of the redbacked shrike in territories in orchards ( $n=21$ food samples) and in wild shrubs ( $n=51$ food samples) in the extensively farmed landscape of eastern Poland

Table 2 Mean numbers of hymenopterans in orchard and wild shrubs (with or without of red-backed shrike's territories) in the extensively farmed landscape of eastern Poland

\begin{tabular}{llll}
\hline Source & Mean & SE & n surveys \\
\hline Orchard with shrikes & 2.2 & 0.34 & 27 \\
Orchard without shrikes & 1.4 & 0.43 & 11 \\
Shrubs with shrikes & 1.6 & 0.48 & 17 \\
Shrubs without shrikes & 1.8 & 0.37 & 33 \\
\hline
\end{tabular}

Table 3 Results of the GLMM analysis assessing effect of agricultural site type (orchard vs. wild shrubs), occurrence/absence of redbacked shrike's territories, season (May-July) and years on the numbers of hymenopteran in the extensively farmed landscape of eastern Poland

\begin{tabular}{lllll}
\hline Variable & Estimate & SE & $F$ & $p$ \\
\hline Agricultural site type & 0.753 & 3.856 & 0.19 & 0.660 \\
Territory presence & 2.557 & 3.442 & 0.74 & 0.391 \\
Season & 9.914 & 3.442 & 2.88 & 0.062 \\
Year & 7.980 & 3.619 & 2.20 & 0.094 \\
\hline
\end{tabular}

\section{Discussion}

The present investigation did not reveal any differences in the numbers of hymenopterans between red-backed shrike territories and areas where these birds were absent. These birds catch relatively large numbers of hymenopterans, which account for $>9 \%$ of their diet. This is in agreement with the results of other studies done in the farming landscape of Poland (Tryjanowski et al. 2003). The diet of the red-backed shrike in eastern Poland was found to contain

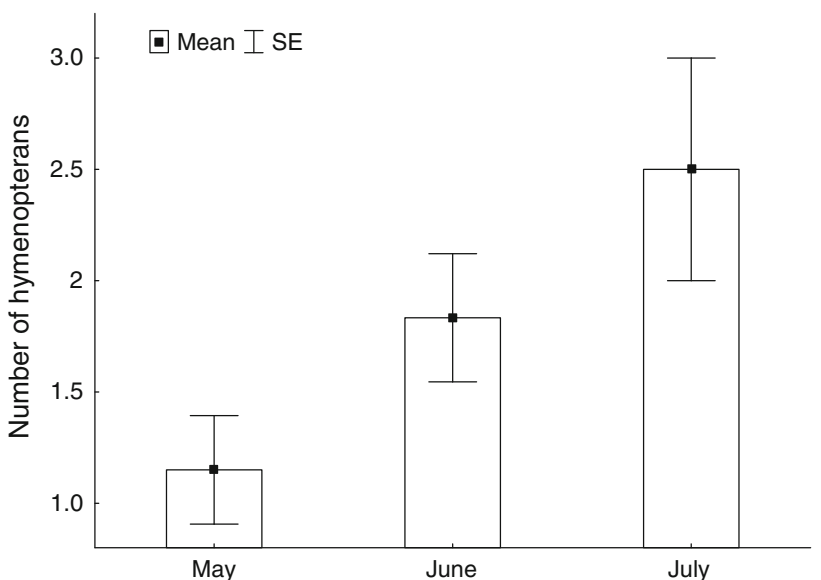

Fig. 3 Mean numbers of hymenopterans on the transects during 3 months in the extensively farmed landscape of eastern Poland

very few representatives of Apidae. The largest numbers of hymenopterans caught were from Vespidae, whose importance as plant pollinators is not as great as that of Apidae. It is therefore likely that red-backed shrikes do not have such a strong influence on hymenopterans from Apidae, which are responsible for pollinating plants, including fruit trees.

The abundance of hymenopterans at our study sites was low-on average two such insects were counted per $50 \mathrm{~m}^{2}$. This was probably due to the lack of beehives in the vicinity, which would have produced large numbers of honey bees, although these can fly up to several $\mathrm{km}$ (even as far as $10 \mathrm{~km}$ ) away from the hive (Beekman and Ratnieks 2000). The density of Apidae species other than honey bees in Poland, even in fields of flowering winter oilseed rape Brassica napus, was $0.5-2.9$ insects $/ 100 \mathrm{~m}^{2}$ (Sądej and Nietupski 2011). But red-backed shrikes arrive in their territories after the fruit trees have blossomed, a time when few hymenopterans remain on them; most will have moved onto flowering herbaceous plants. Red-backed shrikes inhabiting orchards consumed proportionately fewer hymenopterans than their conspecifics with territories in wild shrubs. This may have been due to the greater variety of plants flowering in farmland near wild shrubs (roadside verges, balks, meadows) than in orchards, where the vegetation growing among the trees is regularly mown and does not attract so many hymenopterans, a fact recorded in other studies as well (Dib et al. 2012). The lack of differences in hymenopteran numbers between the orchard and wild shrub transects may be due to the shrikes eliminating these insects in the wild shrubs, which would explain the differences in the proportions of hymenopterans in the shrikes' diet in these two habitats.

To date, the adverse effect of birds on numbers of insect pollinators has been demonstrated in just a few papers. Meehan et al. (2005) found a negative interaction between cliff swallow Hirundo pyrrhonota breeding colonies and 
sweet clover Melilotus officinalis. That study showed that sweet clover fruit set was significantly less near cliff swallow colonies during the nestling period, when the birds consumed very large numbers of insects. In Israel large flocks of migrating bee eaters Merops apiaster were recorded in and around melon Cucumis melo and watermelon Citrullus lanatus plantations. These birds fed on the bees pollinating the flowers of plants in these plantations (Yosef 2004). So by preying on insect pollinators, avian aerial insectivores had an indirect negative impact on insect-pollinated plants. In contrast, the red-backed shrike is a territorial species, nesting in eastern Poland at a density of 2-3 pairs $/ \mathrm{km}^{2}$ (Dombrowski et al. 2000), which is low in comparison with that of swallow species. It is thus likely that low densities of predominately insectivorous bird species have an insignificant effect on insect pollinators, a fact corroborated by Muñoz and Arroyo (2004), who did not find any negative effect of flycatchers Muscisaxicola on the activities of such insects. On the other hand, colony-nesting birds like swallows require suitable nesting sites like high banks or escarpments, and such sites occur only locally. If there happen to be orchards in the vicinity of a breeding colony, then these birds might have some effect on the fruiting of the trees by preying on the insects pollinating them.

Summarising, red-backed shrikes foraged largely on hymenopterans from the family Vespidae; bees from the flower-pollinating family Apidae made up just a small percentage in the diet of these birds. The proportion of hymenopterans in the diet was lower in orchards than in areas supporting wild shrubs. Living as it does in scattered territories, red-backed shrikes in all probability has only a marginal influence on the numbers of pollinating insects (especially in orchards) in the extensively farmed landscape of eastern Poland, with its diversity of habitats and animal assemblages (Tryjanowski et al. 2011).

\begin{abstract}
Acknowledgments We are grateful to Cezary Mitrus for his comments on the manuscript and to Peter Senn for improving the English. We also thank the two anonymous reviewers, who provided valuable comments on the earlier version of the manuscript. The prey composition in the food of the red-backed shrike was identified by Zbigniew Mocarski. This study complies with current Polish laws and was financially supported by the Siedlce University of Natural Sciences and Humanities (Grant 75/94/s to AG).
\end{abstract}

Open Access This article is distributed under the terms of the Creative Commons Attribution License which permits any use, distribution, and reproduction in any medium, provided the original author(s) and the source are credited.

\section{References}

Beekman M, Ratnieks FL (2000) Long-range foraging by the honeybee, Apis mellifera L. Funct Ecol 14:490-496
Cramp S, Perrins CM (1993) Red-backed Shrike Lanius collurio. Handbook of the birds of Europe the Middle East and North Africa, vol VII. Oxford University Press, Oxford

Dib H, Libourel G, Warlop F (2012) Entomological and functional role of floral strips in an organic apple orchard: hymenopteran parasitoids as a case study. J Insect Conserv 16:315-318

Dombrowski A, Golawski A, Kuźniak S, Tryjanowski P (2000) Status and threats of the red-backed Shrike Lanius collurio population in Poland. Not Orn 41:139-148

Donald PF, Pisano G, Rayment MD, Pain DJ (2002) The common agricultural policy, EU enlargement and the conservation of Europe's farmland birds. Agric Ecosyst Environ 89:167-182

Gallai N, Salles J-M, Settele J, Vaissiere BE (2009) Economic valuation of the vulnerability of world agriculture confronted with pollinator decline. Ecol Econ 68:810-821

Golawski A (2006) Comparison of methods for diet analysis and prey preference: a case study on the red-backed Shrike Lanius collurio. Ornis Fennica 83:108-116

Golawski A, Golawska S (2008) Habitat preference in territories of the red-backed Shrike Lanius collurio and their food richness in an extensive agriculture landscape. Acta Zool Acad Sci Hung 54:89-97

Golawski A, Meissner W (2008) The influence of territory characteristics and food supply on the breeding performance of the redbacked Shrike (Lanius collurio) in an extensively farmed region of eastern Poland. Ecol Res 23:347-353

Greenberg R, Bichier P, Angon AC, MacVean C, Perez R, Cano E (2000) The impact of avian insectivory on arthropods and leaf damage in some Guatemalan coffee plantations. Ecology $81: 1750-1755$

Harris T, Franklin K (2000) Shrikes and bush-shrikes. Christopher Helm, London

Hernández A, Purroy FJ, Salgado JM (1993) Seasonal variation, interspecific overlap, and diet selection in three sympatric shrike species (Lanius spp.). Ardeola 40:143-154

Holzschuh A, Dudenhöffer J-H, Tscharntke T (2012) Landscape with wild bee habitats enhance pollination, fruit set and yield of sweet cherry. Biol Conserv 153:101-107

Kuźniak S, Tryjanowski P (2003) The red-backed shrike. Wydawnictwo Klubu Przyrodników, Świebodzin

Marquis RJ, Whelan CJ (1994) Insectivorous birds increase growth of white oak through consumption of leaf-chewing insects. Ecology 75:2007-2014

Meehan TD, Lease HM, Wolf BO (2005) Negative indirect effects of an avian insectivore on the fruit set of an insect-pollinated herb. Oikos 109:297-304

Mols CMM, Visser ME (2002) Great tits can reduce caterpillar damage in apple orchards. J Appl Ecol 39:888-899

Mooney KA, Gruner DS, Barber NA, Van Bael SA, Philpott SM, Greenberg R (2010) Interactions among predators and the cascading effects of vertebrate insectivores on arthropod communities and plants. Proc Natl Acad Sci 107:7335-7340

Muñoz AA, Arroyo MTK (2004) Negative impacts of a vertebrate predator on insect pollinator visitation and seed output in Chuquiraga oppositifolia, a high Andean shrub. Oecologia 138:66-73

Murakami M, Nakano S (2000) Species-specific bird functions in a forest-canopy food web. Proc R Soc Lond B 267:1597-1601

Pettis JS, vanEngelsdrop D, Johnson J, Dively G (2012) Pesticide exposure in honey bees results in increased levels of the gut pathogen Nosema. Naturwissenschaften 99:153-158

Potts SG, Biesmeijer JC, Kremen C, Neumann P, Schweiger O, Kunin WE (2010) Global pollinator declines: trends, impacts and drivers. Trends Ecol Evol 25:345-353

Sądej W, Nietupski M (2011) Evaluation of pollinators' assemblage (Hymenoptera, Apoidea) in winter oilseed rape cultivation. Prog Plant Protect 51:1070-1075 
Sanz J (2001) Experimentally increased insectivorous bird density results in a reduction of caterpillar density and leaf damage to Pyrenean oak. Ecol Res 16:387-394

Semkiw P, Skubida P (2010) Evaluation of the economic aspects of Polish beekeeping. J Apic Sci 54:5-15

Sparks TH, Langowska A, Glazaczow A, Wilkaniec Z, Bienkowska M, Tryjanowski P (2010) Advances in the timing of spring cleaning by the Honeybee Apis mellifera in Poland. Ecol Entomol 35:788-791

StatSoft Inc. (2007) Statistica (data analysis software system), version 8.0. www.statsoft.com

Tryjanowski P, Karg MK, Karg J (2003) Food of the red-backed shrike Lanius collurio: a comparison of three methods of diet analysis. Acta Ornithol 38:59-64

Tryjanowski P, Golawski A, Kuźniak S, Mokwa T, Antczak M (2007) Disperse or stay? Exceptionally high breeding-site infidelity in the red-backed Shrike Lanius collurio. Ardea 95:316-320

Tryjanowski P, Hartel T, Báldi A, Szymański P, Tobolka M, Herzon I, Golawski A, Konvička M, Hromada M, Jerzak L, Kujawa K,
Lenda M, Orłowski G, Panek M, Skórka P, Sparks TH, Tworek S, Wuczyński A, Żmihorski M (2011) Conservation of farmland birds faces different challenges in Western and Central-Eastern Europe. Acta Ornithol 46:1-12

Wratten SD, Gillespie M, Decourtye A, Mader E, Desneux N (2012) Pollinator habitat enhancement: benefits to other ecosystem services. Agric Ecosyst Environ 159:112-122

Yang EC, Chuang YC, Chen YL, Chang LH (2008) Abnormal foraging behavior induced by sublethal dosage of imidacloprid in the honey bee (Hymenoptera: Apidae). J Econ Entomol 101:1743-1748

Yosef R (2004) Resolving the apiculture and migratory bee-eater (Merops apiaster) conflict in the Arava valley, Israel. In: Feare CJ (ed) Advances in vertebrate pest management, vol 3, Flinder, Furth, pp 117-122 